\title{
Bowlegs and Intensive Football Training in Children and Adolescents
}

\author{
A Systematic Review and Meta-Analysis \\ Peter Helmut Thaller*, Julian Fürmetz*, Fuhuan Chen, Nikolaus Degen, Kirsi Marjaana Manz, Florian Wolf
}

\begin{abstract}
Summary
Background: In many countries around the world, football (association football, or "soccer" predominantly in North America) is the sport most commonly played by children and adolescents. It is widely thought that football players are more likely to develop genu varum (bowlegs); an association with knee arthritis also seems likely. The goals of this systematic review and meta-analysis are to provide an overview of the available evidence on genu varum after intensive soccer training in childhood and adolescence, and to discuss the possible pathogenetic mechanisms.
\end{abstract}

Methods: We systematically searched the PubMed, Medline, Embase, and Cochrane Library databases for studies of the relation between leg axis development and intensive football playing during the growing years.

Results: Controlled studies employing the intercondylar distance (ICD) as the target variable were evaluated in a meta-analysis, with the mean difference as a measure of effect strength. This meta-analysis included 3 studies with a total of 1344 football players and 1277 control individuals. All three studies individually showed a significant difference in the mean ICD values of the two groups. The pooled effect estimator for the mean difference was $1.50 \mathrm{~cm}$ (95\% confidence interval [0.53; 2.46]). Two further studies that could not be included in the meta-analysis had similar conclusions. Asymmetrical, varus muscle forces and predominantly varus stress on the osseous growth plates neighboring the knee joint, especially during the prepubertal growth spurt, seem to be the cause of this phenomenon.

Conclusion: Intensive soccer playing during the growing years can promote the development of bowlegs (genu varum) and, in turn, increase the risk of knee arthritis. Physicians should inform young athletes and their parents of this if asked to advise about the choice of soccer as a sport for intensive training. It cannot be concluded, however, that football predisposes to bowlegs when played merely as a leisure activity.

\section{Cite this as}

Thaller PH, Fürmetz J, Chen F, Degen N, Manz KM, Wolf F:

Bowlegs and intensive football training in children and adolescents-a systematic review and meta-analysis. Dtsch Arztebl Int 2018; 115: 401-8.

DOI: 10.3238/arztebl.2018.0401

\section{* Joint first authors}

3D-Surgery, Department of General-, Trauma- and Reconstructive Surgery, University Hospital of Munich (LMU): Dr. Peter Helmut Thaller, Dr. Julian Fürmetz, Fuhuan Chen, Dr. Nikolaus Degen, Dr. Florian Wolf

Institute for Medical Information Processing, Biometry, and Epidemiology (IBE), Ludwig Maximilian University Munich: Kirsi Marjaana Manz, Dipl.-Phys., M. Sc. ootball (soccer) is the most commonly played sport - at both elite and grassroots level in many countries. A survey carried out by the German Olympic Sports Confederation (DOSB) found that football is by far the most popular sport among male children (7 to 14 years) and adolescents (15 to 18 years). For girls in these age groups, football is second only to gymnastics. Overall, it can be assumed that around 1.65 million boys and 300000 girls in Germany currently play football on an organized basis (1). The consequences of football in terms of typical injuries and their prevention have been the subject of numerous studies (2). Both professional and amateur sports players have been reported to have an elevated prevalence of osteoarthritis in later years (3). In the general population many factors contribute to the pathogenesis of osteoarthritis (4), but in elite sportsmen and -women a central role is played by the strains and injuries specific to the respective sport (5-7). Professional footballers who have never suffered a major injury to the knee joint have a significantly (1.3-fold) elevated risk of knee osteoarthritis; the increase in risk is even greater (2.9-fold) if footballers with knee injuries are included (8). Alongside the increased prevalence of knee joint problems in general and osteoarthritis in particular, ex-professional football players have been found to have a high (55 to 63\%) incidence of genu varum (bowlegs) (9). For adults there is strong evidence that genu varum accelerates the progress of knee osteoarthritis (10). It is even highly probable that genu varum is an independent risk factor for the initial onset of knee osteoarthritis (11, 12). Several pathomechanisms have been proposed as causes of football-associated genu varum, e.g., muscular dysequilibrium and asymmetric overloading of the growth plates (13-17). Overall, however, little in the way of epidemiological or biomechanical data is available on this potential consequence of intensive football playing during the growth phase.

We carried out a systematic review and metaanalysis to investigate the risk for development of genu varum from intensive football training in childhood and adolescence and identify possible pathomechanisms.

\section{Methods}

Two of us (PHT, FC) carried out a systematic survey of the literature in the databases Medline, PubMed, Embase, 
FIGURE 1

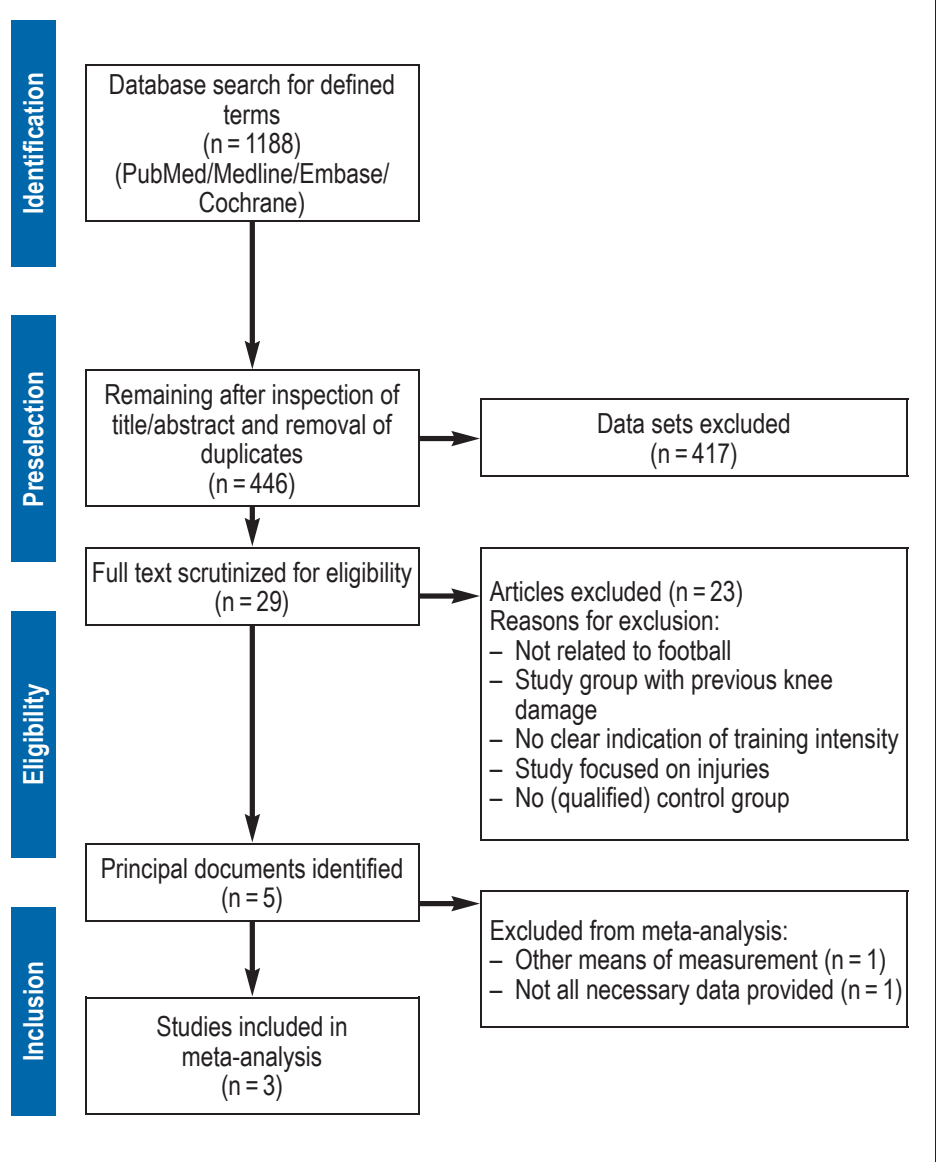

Flow chart showing the systematic literature survey

and Cochrane Library to find publications on the topic of a possible link between football playing in childhood and adolescence and development of genu varum. The publications identified as potentially relevant were read in full, and for the studies selected for review we also scrutinized the references for relevant publications. The documents were examined to sift out not only epidemiological data but also information on the pathogenesis of sports-related genu varum. Differences in the results of the literature survey were discussed and a consensus reached between the two investigators (for the structured approach to the literature survey, see Figure 1). The following search terms were used, individually and in groups connected with "AND": "football", "soccer", "child/children", "adolescent/adolescence", "varus knee", "knee varum", "genu varum", "bowlegs". The possible combinations were also connected ("AND") with the following individual terms: "biomechanics", "joint", "growth plates", "lower leg alignment", "muscle contraction", "osteoarthritis", "muscle contraction", "risk factors", "fatigue", "collateral ligament", "adductive muscle", "anterior cruciate ligament", "growth deformity," and "high activity sports". The systematic review was registered in PROSPERO (ID 97109).
After selection of the studies containing epidemiological data, the Newcastle-Ottawa Scale (NOS) (18) was used to assess the quality of the publications and determine their eligibility for statistical analysis. The full text of the articles was then scrutinized and the data needed for analysis were extracted. Since the clinical evaluation of intercondylar distance (ICD) or intermalleolar distance (IMD) is the conventional way of determining the leg axis in children (Figure 2), we focused on the relationship between playing football during the growth phase and ICD as a measure of bowlegs or IMD as a measure of knock-knees. Because growth and development of lower limb geometry differ considerably between the sexes, only controlled studies with males were included. The probands of all the studies included were young highperformance footballers following intensive training programs. The presence of data on mean ICD/IMD and their standard deviation was a criterion for inclusion in the meta-analysis.

The DerSimonian and Laird random-effects model with inverse variance weighting of the individual studies (23) was used for meta-analysis. Because the outcome (ICD/IMD value) is continuous, the mean difference (MD) between the football players and the control group was chosen as the measure of effect for the meta-analysis. The extracted means and standard deviations for individual age groups were pooled to obtain comparable age categories. The software R (version 3.4.3) was used for all statistical analyses.

\section{Results \\ Literature search and selection}

The systematic literature survey identified 1188 potentially relevant documents (Figure 1). After detailed screening of titles and abstracts and removal of duplicates, 29 articles remained for full-text evaluation. Six of these publications contained epidemiological data on the occurrence of bowlegs in pre-adult footballers. One very early study, published in 1950 (24), had to be excluded owing to the absence of control groups and deficient methods (measurement of ICD in finger breadths).

The five remaining studies were basically of good systematic quality and scored at least 6 points on the NOS (18) (Table 1). Four of the five fulfilled the above-mentioned criteria for meta-analysis and had basically comparable methods of measuring ICD/ $\operatorname{IMD}(13,14,16,17)$. The study by Colyn et al. (15) could not be analyzed together with these four publications because of its differing (radiographic) method of measurement (Table 2). The methodically sound study by Yaniv et al. (17) could not be used for quantitative evaluation due to the absence of standard deviations. The remaining three studies $(13,14,16)$ contained all the data required for meta-analysis.

\section{Studies included in the meta-analysis}

Abreu et al. (14) found premature alteration of the leg axis from valgus to varus in a majority of football players 
as young as 12. In the control group, the leg axes only became predominantly varus from the age of 16 years onward. The prevalence of bowlegs among young footballers was $73.3 \%$, approaching double that in boys of the same age who were not active sports players $(40.6 \%)$. The authors assumed that varization of the leg axis in football players is caused by repeated microtrauma to the growth plates above and below the knee. They discussed the possibility of selection bias: children with bowlegs are thought to be better at football and may therefore receive more encouragement.

Witvrouw et al. (16) used a positioning guide in measuring the ICD of footballers from two top-class clubs in Belgium. The control group comprised athletes with similarly high performance who did not play football. The 16- to 18-year old football players had a significantly $(\mathrm{p}=0.028)$ higher rate of varus leg axis. The authors assumed a football-specific dysequilibrium of the leg muscles to be the main reason.

Asadi et al. (13) found significantly higher ICD in probands who played football for more than $6 \mathrm{~h}$ each week than in boys of the same age who played football for less than $6 \mathrm{~h}$ per week $(3.01 \mathrm{~cm}$ versus $2.28 \mathrm{~cm} ; \mathrm{p}=0.0001)$. The prevalence of bowlegs in the footballers was also significantly greater than in a subgroup of the controls who played other sports (basketball, volleyball, handball) that could be assumed to feature similar stresses from cutting maneuvers. The authors postulated that the reason lay in movements specific to football, such as shooting for goal.

\section{Meta-analysis}

Altogether, $\mathrm{n}=1344$ footballers and 1277 controls were investigated. All $n=3$ studies included in the metaanalysis showed a significant MD in ICD/IMD between football players and controls; the groups of footballers always showed higher mean ICD values. The pooled effect estimator for the MD from the random-effects model was $1.50 \mathrm{~cm}(95 \%$ confidence interval [0.53; 2.46]). The fixed-effects model yielded an overall estimator of $0.75 \mathrm{~cm}([0.64 ; 0.86])$. There was significant heterogeneity among the studies $\left(\mathrm{I}^{2}=96 \%, \mathrm{p}<0.01\right)$ (Figure 3).

For $\mathrm{n}=2$ studies common age groups could be formed. The mean ICD/IMD measurements per age group are shown in Figure 4.

\section{Discussion}

The physiological development of the leg axis in the first 10 years of life is a dynamic process. The varus alignment of infancy gradually changes to valgus, attaining a maximum at the age of around 5 years. This valgus decreases continually during the rest of the growth phase, and the physiological tibiofemoral angle (TFA) in adulthood is 5 to $7^{\circ}$, usually corresponding to a centered mechanical leg axis $(22,25$, 26). Epidemiological investigations in children and adolescents are restricted to clinical examinations such as the measurement of ICD and IMD or observational

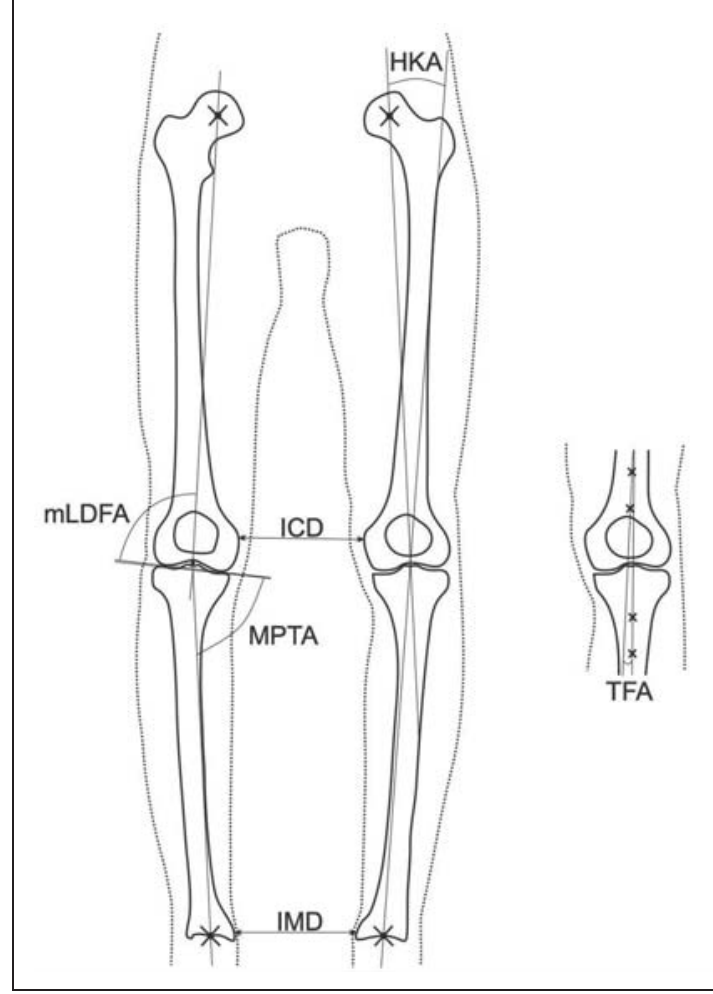

Clinical and radiological assessment of lower limb geometry (modified from [19-22])

HKA, Hip-knee angle;

ICD, intercondylar distance;

IMD, intermalleolar distance;

mLDFA, mechanical lateral distal femoral angle;

MPTA, medial proximal femoral angle;

TFA, tibiofemoral angle

studies; precise determination of the leg axis by radiography cannot be justified in healthy persons. Since the value of the existing studies lies primarily in identification of differences between the study groups and the control groups, a meta-analysis of the published data seems particularly appropriate. One weakness of our review is the small number of relevant studies and their limited comparability. The fact that in all studies the hypothesis was confirmed strongly suggests that further research is warranted.

Our random-effects meta-analysis showed that intensive football playing in childhood and adolescence has a significant effect on the leg axis. Despite the high study quality (Table 1), the results of the studies are heterogeneous. A fixed-effects model would yield a (significantly) smaller pooled MD, because the study by Asadi et al. (13) is weighted particularly heavily due to the large number of cases and thus contributes almost exclusively to the overall estimator. Several factors may contribute to the heterogeneity. For instance, Witvrouw et al. (16), unlike the authors of the other studies, used movable footplates to avoid 
TABLE 1

Characteristics of the epidemiological studies and their scores on the Newcastle-Ottawa Scale

\begin{tabular}{|c|c|c|c|c|c|c|c|c|c|}
\hline \multirow[t]{2}{*}{ Publication } & \multicolumn{4}{|c|}{ Selection } & \multirow{2}{*}{$\begin{array}{l}\text { Comparability } \\
\text { Comparability of } \\
\text { cases and controls }\end{array}$} & \multicolumn{3}{|c|}{ Exposure } & \multirow[t]{2}{*}{ Total score } \\
\hline & $\begin{array}{l}\text { Adequate } \\
\text { case } \\
\text { definition }\end{array}$ & $\begin{array}{l}\text { Representative- } \\
\text { ness of cases }\end{array}$ & $\begin{array}{l}\text { Selection of } \\
\text { controls }\end{array}$ & $\begin{array}{l}\text { Definition of } \\
\text { controls }\end{array}$ & & $\begin{array}{c}\text { Determination } \\
\text { of exposure }\end{array}$ & $\begin{array}{l}\text { Same } \\
\text { method }\end{array}$ & $\begin{array}{l}\text { Exclusion } \\
\text { rate }\end{array}$ & \\
\hline $\begin{array}{l}\text { Witvrouw } 2009 \\
\text { (16) }\end{array}$ & * & * & * & & * & * & * & & 6 \\
\hline $\begin{array}{l}\text { Yaniv } 2006 \\
\text { (17) }\end{array}$ & * & & * & * & * & * & * & & 6 \\
\hline $\begin{array}{l}\text { Asadi } 2015 \\
\text { (13) }\end{array}$ & * & * & * & * & ** & * & * & & 8 \\
\hline $\begin{array}{l}\text { Colyn } 2016 \\
(15)\end{array}$ & * & * & * & * & * & * & * & * & 8 \\
\hline $\begin{array}{l}\text { Abreu } 1996 \\
\text { (14) }\end{array}$ & * & * & * & & * & * & * & & 6 \\
\hline
\end{tabular}

\section{TABLE 2}

\section{Participants and parameters measured in the epidemiological studies}

\begin{tabular}{l|c|c|c|c|c}
\hline Authors & Country & Boys & Girls & Age (years) & Parameter \\
\hline Witvrouw 2009 (16) & Belgium & 794 & 0 & $8-18$ & ICD/IMD \\
\hline $\begin{array}{l}\text { Yaniv } 2006 \\
(17)\end{array}$ & Israel & 174 & 0 & $10-21$ & ICD/IMD \\
\hline $\begin{array}{l}\text { Asadi } 2015 \\
(13)\end{array}$ & Iran & 1500 & 0 & $10-18$ & Radiological determination of joint angle \\
\hline $\begin{array}{l}\text { Colyn 2016 } \\
(15)\end{array}$ & Belgium & 100 & 100 & $10-17$ & ICD/IMD \\
\hline $\begin{array}{l}\text { Abreu 1996 } \\
(14)\end{array}$ & Brazil & 327 & 85 & $12-17$ & \\
\hline
\end{tabular}

ICD, intercondylar distance; IMD, intermalleolar distance

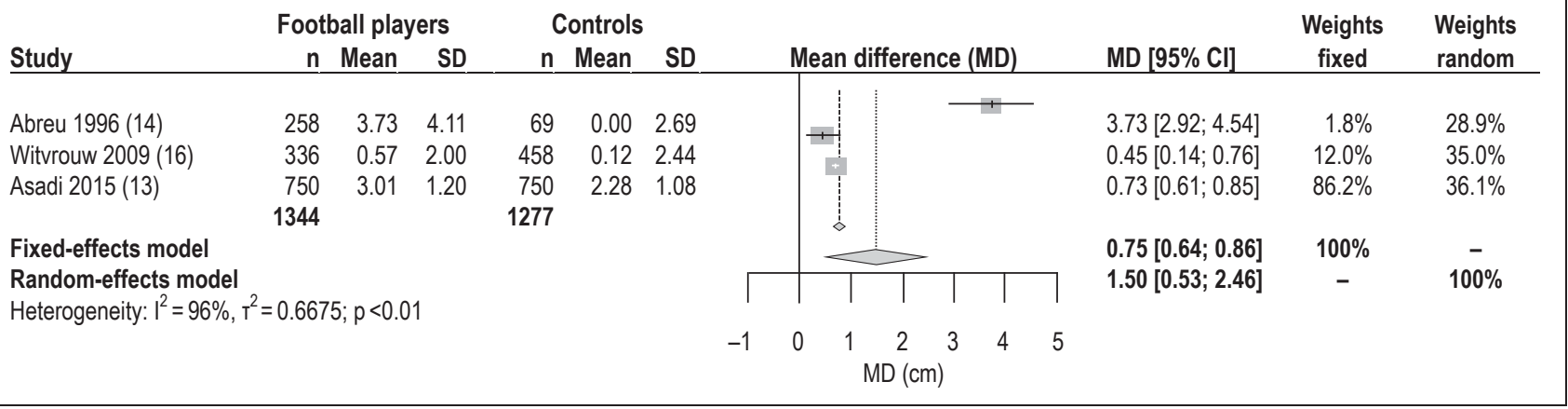

Forest plot of the analyzed studies. The vertical line corresponds to the null effect, where no there is no difference between the means of the two groups being compared. The diamonds represent the pooled overall estimates from the fixed-effect and the random-effects model; the width of each diamond indicates the confidence interval of the overall estimate.

$\mathrm{n}$, total; SD, standard deviation; $95 \% \mathrm{Cl}, 95 \%$ confidence interval 

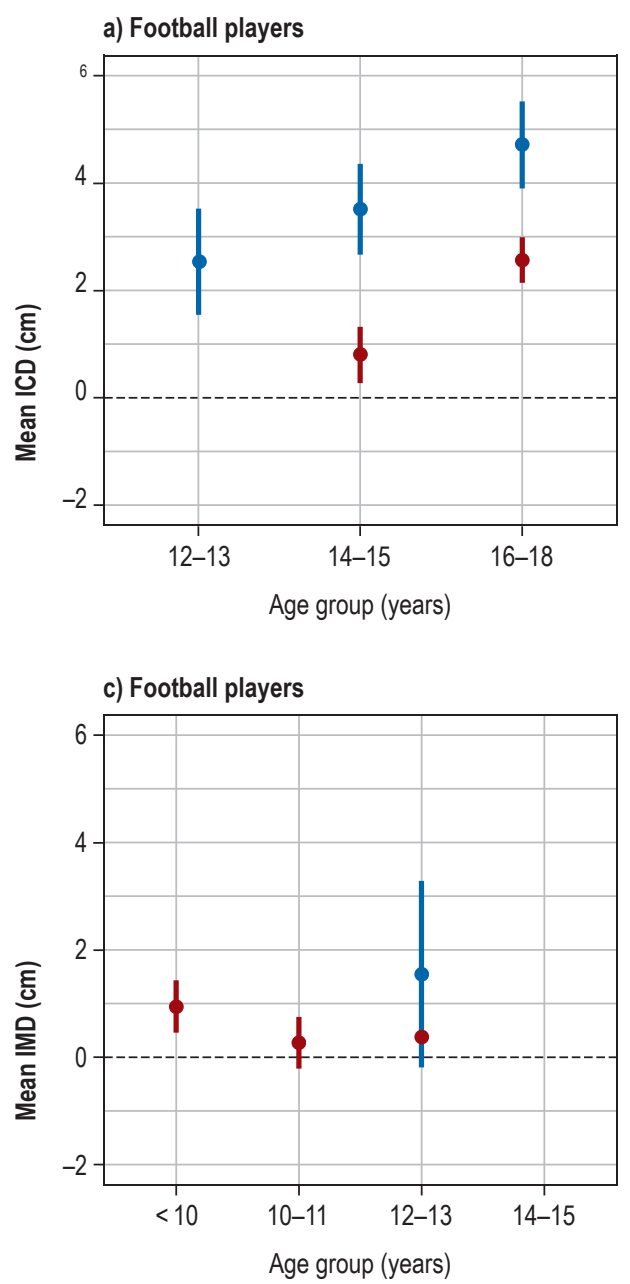

\section{b) Controls}

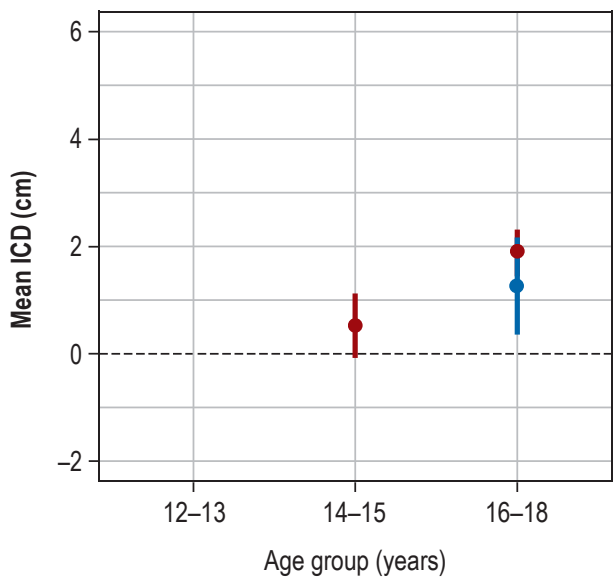

d) Controls

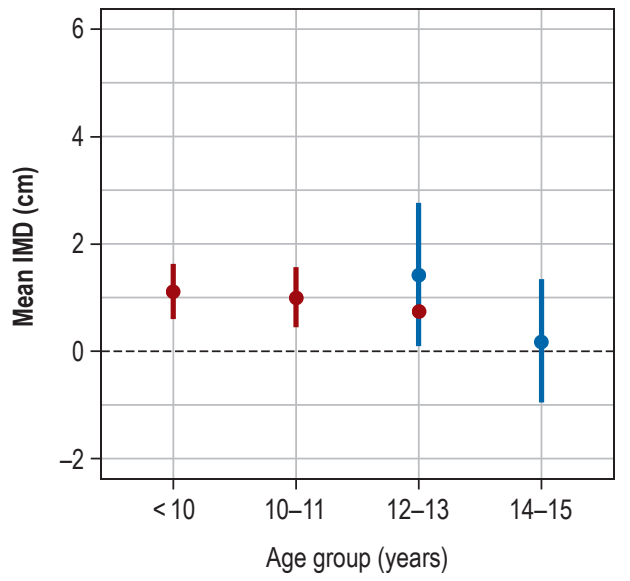

Mean ICD/IMD and $95 \%$ confidence intervals by age group for football players $(a, c)$ and control groups (b, d) ICD, intercondylar distance; IMD, intermalleolar distance muscular tension during measurements. Moreover, the control groups of the three studies were not identical: Abreu et al.'s (14) control group comprised boys of the same age who were not especially active, while that of Witvrouw et al. (16) was made up of adolescents who played other sports at a similar level of intensity. Asadi et al. (13) divided their control group into subgroups based on the number of hours of football per week together with other sporting activity. Finally, given that the studies were carried out in different countries, the measured values may have been influenced by unquantified ethnic and sociocultural differences among the study groups.

In the case-control studies by both Abreu et al. (14) and Witvrouw et al. (16), genu varum was much more pronounced in the older subgroups. Abreu et al. (14) observed a transition from a physiologically mostly valgus leg axis to predominantly varus lower limb geometry in boys as young as 12 , whereas Witvrouw et al. (16) saw this change from the age of 14 upwards. No valid statement can be made with regard to the training intensity and methods of the various football clubs. Our requests for information about study details and unpublished data went unanswered. Owing to the low number of studies and the associated difficulty of reliably detecting publication bias, no funnel plot was generated.

\section{Discussion of the studies not included in the meta-analysis}

In the study by Colyn et al. (15), young adults were questioned about their sporting activity in childhood and the results were correlated with lower limb geometry on whole-leg radiographs. There was a subgroup analysis 


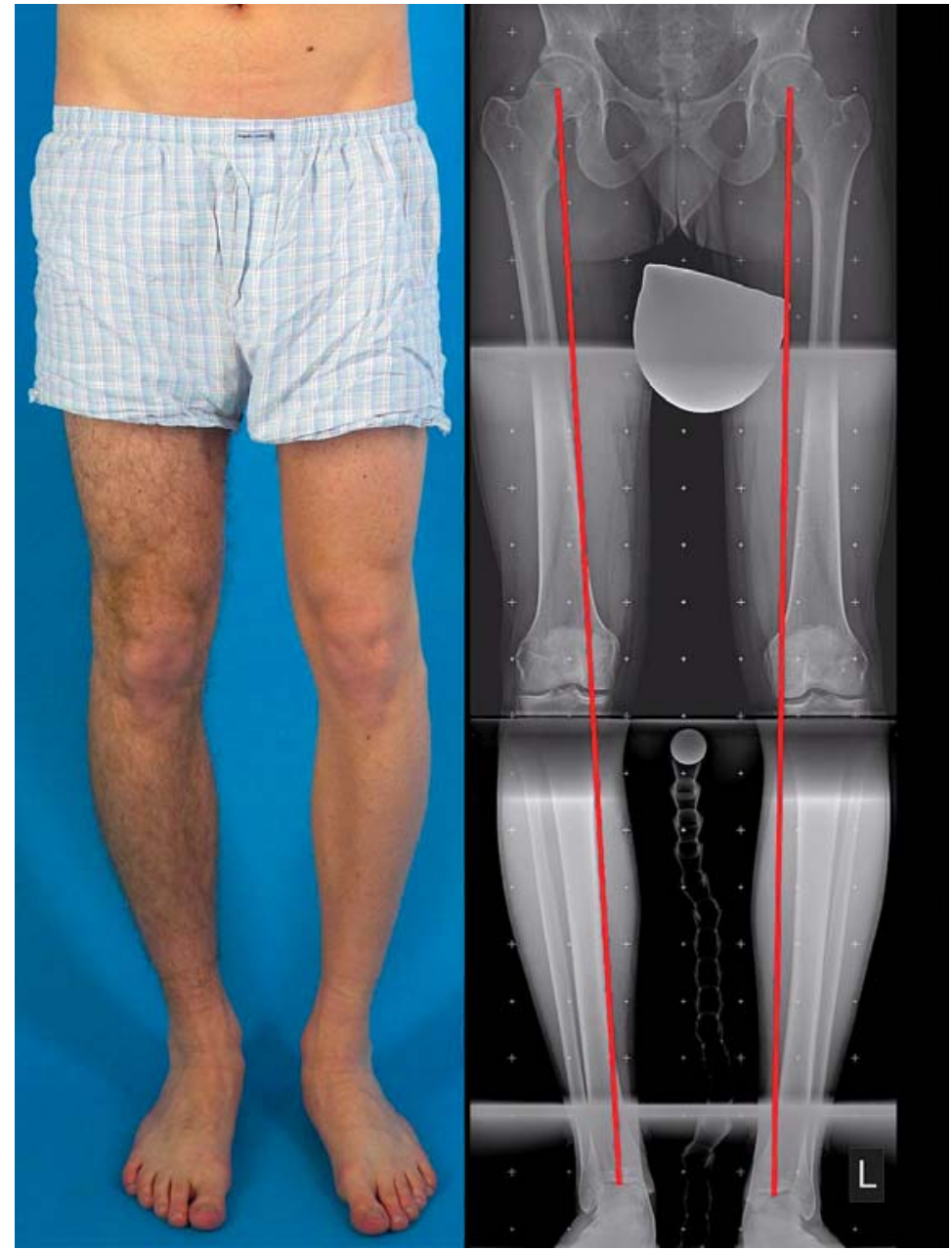

Figure 5: Bilateral varus deformity of the leg axis resulting from malalignment of the proximal tibia. Medial proximal femoral angle (MPFA) (Figure 1): right $83^{\circ}$, left $81^{\circ}$ (normal range $\left.85-90^{\circ}\right)$ additional stress mechanisms in football, e.g., shooting, as a potential reason for the higher prevalence of bowlegs, but also drew attention to the possibility of selection bias due to potential advantages conveyed by genu varum, such as better balance during dribbling and changes of direction.

The results of both studies show that even in comparison with other high-impact sports, football particularly favors the development of genu varum. With the aid of our systematic literature survey, we sought to identify football-specific pathomechanisms.

\section{Possible pathomechanisms}

Changes of direction while running cause increased mechanical strain (27); furthermore, dynamic knee joint stabilization decreases with increasing neuromuscular fatigue and the rate of injuries rises (28-30). Independently, the cleated shoes worn by footballers restrict external rotation in the stance phase and increase the varus load on the knee joint (31). Some authors are of the opinion that the adductor muscles are a decisive factor in the development of varus deformity $(13,16,17)$. Relevant injuries are more likely $(56 \%)$ to affect the leg predominantly used for shooting (32). The adductor muscles do not overlap the knee joint, however, and varus deformities in various specific sports show no difference between the weight-bearing leg and the shooting leg (15).

In contrast, the so-called hamstrings (the semitendinosus, semimembranosus, and biceps femoris muscles) overlap both of the growth plates in the vicinity of the knee, with the pulling force exerted on the medial aspect being twice as high as that exerted on the lateral aspect. This is the most frequently injured group of muscles among football players (32, 33).

The growth plates above and below the knee joint generate most of the growth in leg length and, for geometric reasons, exert the greatest effect on the leg axis. Especially in the prepubertal rapid growth phase, overloading due to trauma or chronic, repetitive dysequilibrium can lead to asymmetric growth $(34,35)$. The medial tibial growth plate seems particularly vulnerable (Figure 5) (15).

\section{Conclusion}

The published data indicate that the risk of bowlegs is increased in adolescents who spend a very large amount of time playing football. However, the mean values of the studies included in our meta-analysis were strongly heterogeneous, although in all studies the groups of football players showed higher mean ICD values compared to control groups. One possible reason for the heterogeneity is the varying degree of sporting activity in the respective control groups. All three studies investigated high-performing male footballers who were still growing, but the precise intensity of training is not described. We do not believe it would be appropriate to extrapolate our findings to sporting activity at less intensive levels. In adults genu varum has been shown to be a 
risk factor for more rapid progress of knee osteoarthritis. Despite the limited amount of data published to date, genu varum can be assumed to represent an independent risk factor for the development of knee osteoarthritis. Chronic, repetitive asymmetric overloading of the growth plates in the vicinity of the knee joint and tension on the hamstring muscles may be responsible for the development of varus deformity of the leg axis. The tibial growth plate seems to be more vulnerable than its femoral counterpart. The most sensitive age is the prepubertal phase of rapid growth.

Further research by sports scientists and physicians is necessary to elucidate the pathomechanisms and work out specific strategies for prevention. Special training measures, e.g., to improve dynamic knee joint stability, may be helpful in this regard, together with modified footwear and adjustment of training intensity for the most vulnerable age group.

\section{Conflict of interest statement}

The authors declare that no conflict of interest exists.

Manuscript submitted on 3 May 2018, revised version accepted on 30 May 2018

Translated from the original German by David Roseveare

\section{References}

1. Deutscher Olympischer Sportbund (DOSB): Bestandserhebung 2017. Aktualisierte Fassung vom 25. Januar 2018. https://cdn.dosb.de/ user_upload/www.dosb.de/uber_uns/Bestandserhebung/BEHeft_2017_aktualisierte_Version_25.01.18.pdf (last accessed on 23 May 2018).

2. Olsen L: Strategies for prevention of soccer related injuries: a systematic review. Br J Sports Med 2004; 38: 89-94.

3. Driban JB, Hootman JM, Sitler MR, Harris KP, Cattano NM: Is participation in certain sports associated with knee osteoarthritis? A systematic review. J Athl Train 2017; 52: 497-506.

4. Chaganti RK, Lane NE: Risk factors for incident osteoarthritis of the hip and knee. Curr Rev Musculoskelet Med 2011; 4: 99-104.

5. Spector TD, Harris PA, Hart DJ, et al.: Risk of osteoarthritis associated with long-term weight-bearing sports: a radiologic survey of the hips and knees in female ex-athletes and population controls. Arthritis Rheum 1996; 39: 988-95.

6. Lohmander LS, Ostenberg A, Englund M, Roos H: High prevalence of knee osteoarthritis, pain, and functional limitations in female soccer players twelve years after anterior cruciate ligament injury. Arthritis Rheum 2004; 50: 3145-52.

7. Petrillo S, Papalia R, Maffulli N, Volpi P, Denaro V: Osteoarthritis of the hip and knee in former male professional soccer players. Br Med Bull 2018; 125: 121-30

8. Spahn G, Grosser V, Schiltenwolf M, Schröter F, Grifka J [Football as risk factor for a non-injury-related knee osteoarthritis - results from a systematic review and metaanalysis]. Sportverletz Sportschaden Organ Ges Orthopadisch-Traumatol Sportmed. 2015; 29: 27-39.

9. Arliani GG, Astur DC, Yamada RKF, et al.: Early osteoarthritis and reduced quality of life after retirement in former professional soccer players. Clinics 2014; 69: 589-94.

10. Tanamas S, Hanna FS, Cicuttini FM, Wluka AE, Berry P, Urquhart DM: Does knee malalignment increase the risk of development and progression of knee osteoarthritis? A systematic review. Arthritis Rheum 2009; 61: 459-67.

11. Brouwer GM, Tol AWV, Bergink AP, et al.: Association between valgus and varus alignment and the development and progression of radiographic osteoarthritis of the knee. Arthritis Rheum 2007; 56: 1204-11.

12. Tetsworth K, Paley D: Malalignment and degenerative arthropathy. Orthop Clin North Am 1994; 25: 367-77.

\section{Key messages}

- A systematic review of the literature around the influence of football on the development of genu varum identified 29 publications directly related to the topic, including five studies with epidemiological data.

- All five of the epidemiological studies point to a connection between intensive football playing by children and adolescents and the risk of varus deformity of the leg axis.

- The meta-analysis showed a significantly higher mean intercondylar distance $(1.5 \mathrm{~cm}, 95 \%$ confidence interval $[0,53 ; 2,46])$ in footballers than in controls.

- Sport-specific overloading of the growth plates above and below the knee joint can be assumed to be the most likely pathomechanism.

- The necessity of further research and development of measures to prevent genu varum is underlined by the high number of young people potentially affected.

13. Asadi K, Mirbolook A, Heidarzadeh A, et al.: Association of soccer and genu varum in adolescents. Trauma Mon 2015; 20: e17184.

14. Abreu AVD, Barbosa JRP, Paiva FJD: Alinhamento dos joelhos no plano frontal dos 12 aos 17 anos [Alignment of the knees in the frontal plane from 12 to 17 years]. Braz J Phys Ther 1996; 31: 6.

15. Colyn W, Agricola R, Arnout N, Verhaar JAN, Bellemans J: How does lower leg alignment differ between soccer players, other athletes, and non-athletic controls? Knee Surg Sports Traumatol Arthrosc 2016; 24: 3619-26.

16. Witvrouw E, Danneels L, Thijs Y, Cambier D, Bellemans J: Does soccer participation lead to genu varum? Knee Surg Sports Traumatol Arthrosc 2009; 17: 422-7.

17. Yaniv M, Becker T, Goldwirt M, Khamis S, Steinberg DM, Weintroub S: Prevalence of bowlegs among child and adolescent soccer players: Clin J Sport Med 2006; 16: 392-6.

18. Stang A: Critical evaluation of the Newcastle-Ottawa scale for the assessment of the quality of nonrandomized studies in meta-analyses. Eur J Epidemiol 2010; 25: 603-5.

19. Arazi M, Öğün TC, Memik R: Normal development of the tibiofemoral angle in children: a clinical study of 590 normal subjects from 3 to 17 years of age. J Pediatr Orthop 2001; 21: 264-7.

20. Paley D, Tetsworth K: Mechanical axis deviation of the lower limbs: preoperative planning of uniapical angular deformities of the tibia or femur. Clin Orthop 1992; 280: 48-64.

21. Moreland JR, Bassett LW, Hanker GJ: Radiographic analysis of the axial alignment of the lower extremity. J Bone Jt Surg 1987; 69 : 745-9.

22. Salenius $P$, Vankka $E$ : The development of the tibiofemoral angle in children. J Bone Joint Surg Am 1975; 57: 259-61.

23. DerSimonian $\mathrm{R}$, Laird N: Meta-analysis in clinical trials revisited. Contemp Clin Trials 2015; 45: 139-45.

24. Wassen H: [Does soccer cause bowlegs?]. Med Klin 1950; 45: 562-3.

25. Baruah RK, Kumar S, Harikrishnan SV: Developmental pattern of tibiofemoral angle in healthy north-east Indian children. J Child Orthop 2017; 11: 339-47.

26. Heath $\mathrm{CH}$, Staheli LT: Normal limits of knee angle in white childrengenu varum and genu valgum. J Pediatr Orthop 1993; 13: 259-62.

27. Besier TF, Lloyd DG, Cochrane JL, Ackland TR: External loading of the knee joint during running and cutting maneuvers. Med Sci Sports Exerc 2001; 33: 1168-75.

28. Coventry E, O'Connor KM, Hart BA, Earl JE, Ebersole KT: The effect of lower extremity fatigue on shock attenuation during single-leg landing. Clin Biomech Bristol Avon 2006; 21: 1090-7.

29. Nyland JA, Caborn DNM, Shapiro R, Johnson DL: Crossover cutting during hamstring fatigue produces transverse plane knee control deficits. J Athl Train 1999; 34: 137-43.

30. Savage RJ, Lay BS, Wills JA, Lloyd DG, Doyle TLA: Prolonged running increases knee moments in sidestepping and cutting manoeuvres in sport. J Sci Med Sport 2018; 21: 508-12. 
31. Andrews M, Noyes FR, Hewett TE, Andriacchi TP: Lower limb alignment and foot angle are related to stance phase knee adduction in normal subjects: a critical analysis of the reliability of gait analysis data. J Orthop Res Off Publ Orthop Res Soc 1996; 14: 289-95.

32. Hägglund $M$, Waldén $M$, Ekstrand $\mathrm{J}$ : Risk factors for lower extremity muscle injury in professional soccer: the UEFA Injury Study. Am J Sports Med $2013 ; 41: 327-35$.

33. Lynn SK, Costigan PA: Effect of foot rotation on knee kinetics and hamstring activation in older adults with and without signs of knee osteoarthritis. Clin Biomech 2008; 23: 779-86.

34. Langenskiöld A, Riska EB: Tibia vara (osteochondrosis deformans tibiae): a survey of seventy-one cases. J Bone Joint Surg Am 1964; 46: 1405-20.

35. Cook SD: A biomechanical analysis of the etiology of tibia vara. J Pediatr Orthop 1983: 3: 449-54.

\section{Corresponding author}

Dr. med. Peter Helmut Thaller

Arbeitsgruppe 3D-Chirurgie

Klinik für Allgemeine, Unfall- und Wiederherstellungschirurgie

Klinikum der Ludwig-Maximilians-Universität München

Campus Innenstadt

Nußbaumstr. 20

80336 München, Germany

pthaller@med.Imu.de 